\title{
Erratum to: Genetics in the medical and psychosocial practice: on the role of value hierarchies in counselling
}

\author{
Brigitte Gschmeidler $^{1}$ • Magdalena Flatscher-Thöni ${ }^{1}$ - Elke Knitel-Grabher ${ }^{1}$
}

Published online: 22 May 2017

(C) Springer-Verlag Berlin Heidelberg 2017

Erratum to: J Public Health (2016) 24:253-261

DOI 10.1007/s10389-016-0719-6

The original article contains an error in the following paragraph (page 258, column 1, paragraph 2):

Among the psychosocial professionals, $26 \%(n=5)$ considered values to have no influence on the counselling session; $47 \%$ $(n=9)$ saw values as somewhat influential, $21 \%(n=4)$ estimated the influence rather high, and one person ( $5 \%$ ) considered values to have a very high influence on the counselling.

The corrected version should be:

Among the psychosocial professionals, no one considered values to have no influence at all on the counselling session; $26 \%(n=5)$ viewed values as somewhat not influential on the counselling session, $47 \%(n=9)$ saw values as somewhat influential, $21 \%(n=4)$ estimated the influence rather high, and one person $(5 \%)$ considered values to have a very high influence on the counselling.

The online version of the original article can be found at http://dx.doi.org/ 10.1007/s10389-016-0719-6

Brigitte Gschmeidler

brigitte.gschmeidler@umit.at

1 Department of Public Health and Health Technology Assessment, UMIT - Private University of Health Sciences, Medical Informatics and Technology, Hall/Tirol, Austria 